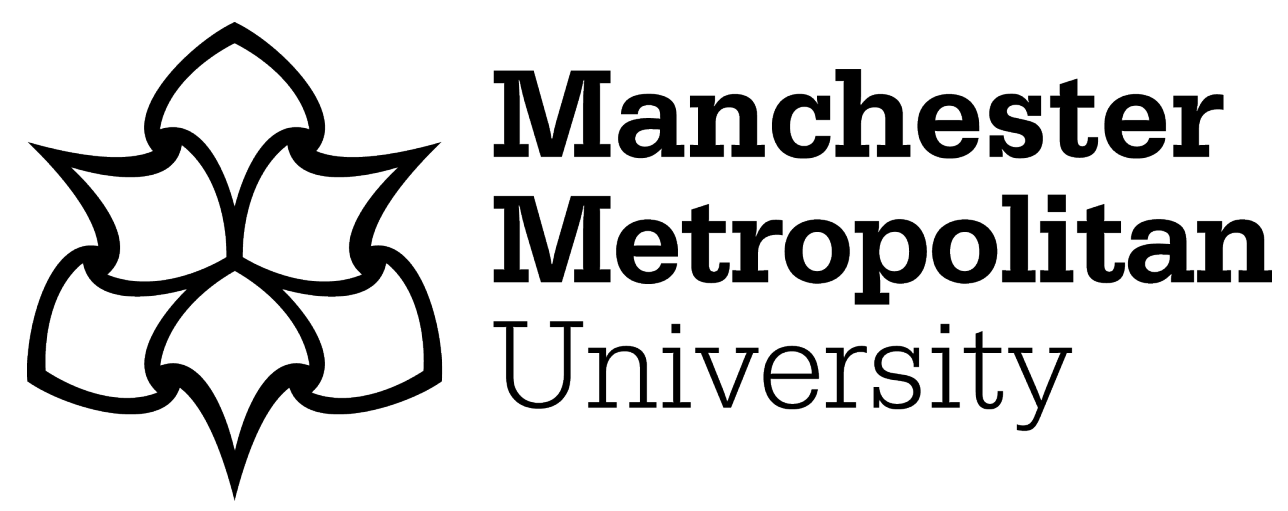

Álvares, Cláudia, Martins, Inês Rôlo and Cardoso, Daniel Dos Santos (2013) Argumentação numa esfera pública reticular: as vozes femininas online. Comunicação \& Informação, 14 (2). ISSN 1415-5842

Downloaded from: https://e-space.mmu.ac.uk/627513/

Version: Published Version

Publisher: Universidade Federal de Goias

DOI: https://doi.org/10.5216/cei.v14i2.22444

Please cite the published version 


\title{
Argumentação numa esfera pública reticular: as vozes femininas online $^{1}$
}

\author{
Cláudia Álvares ${ }^{2}$ \\ (claudia.alvares@ulusofona.pt) \\ Inês Rôlo Martins ${ }^{3}$ \\ (inesrmartins@gmail.com) \\ Daniel dos Santos Cardoso ${ }^{4}$ \\ (danielscardoso@gmail.com)
}

\begin{abstract}
Resumo
Se as novas tecnologias não garantem, em si mesmas, o surgimento de uma nova ordem social, abrem ainda assim possíveis novos espaços de participação política e cívica. Partindo de uma concepção de espaço público habermasiano centralizado, uno e masculino, para a multiplicidade de contra-públicos evidenciados pelas críticas feministas e potenciados pela tecnologia da Internet, indagamos das condições de existência de esferas públicas femininas em fóruns e na blogosfera. Até que ponto a ligação reticular dos sujeitos online permite que as vozes femininas tenham um lugar de produção a partir das suas diferenças e das suas possíveis exclusões e marginalidades?
\end{abstract}

Palavras-chave: Esferas Públicas. Contra-esferas. Deliberação. Mulheres. Redes. Crítica Feminista.

\section{Argumentation in a reticular public sphere: female voices online}

\begin{abstract}
Although new communication technologies cannot ensure a new social order, they nevertheless open up new spaces of possibility for political and civic participation. Departing from a centralised, unified and masculinised habermasian conception of public space, and focusing on the multitude of counter-publics formed by feminist critiques and fuelled by the Internet, we aim to explore the existence and characteristics of feminine public spheres in forums and blogs so as to inquire into the extent to which reticulate linking of online subjects allows female voices to have a locus of production stemming from their differences, possible exclusions and margins.
\end{abstract}

Keywords: Public Spheres. Counter-spheres. Deliberation. Women. Networks. Feminist Criticism.

$\ll \ldots$ how to place the non-present woman in ontology, epistemology and metaphysics; how to theorize, and, ideally,

1 Este artigo integra o Projecto PIHM/GC/0129/2008 - Participação Feminina Online: A Redefinição da Esfera Pública - financiado pela Fundação para a Ciência e Tecnologia e coordenado por Cláudia Álvares.

CICANT/ULHT .

CICANT.

CICANT/ULHT/UNL-FCSH. 
enact, a subjectivity for she who is not a subject in discourse.» (WISE, 1997).

Se as minorias podem ser afastadas do espaço público porque a cultura tende a ser dominante e centrada sobre si própria, empurrando-as para as margens, a deliberação pretende ser uma forma de atrair essas margens, a partir das teorias de democracia participativa (in SILVEIRINHA, 2005, p. 157). Reflectindo a preocupação de Wise e das críticas feministas das teorias do espaço público, é este o desafio a que nos propomos dar resposta, por mais parcial e restrita que esta seja. Com a identidade a ser vista como uma construção negociada pela relação com os outros, num processo de sistemática definição dos seus contornos (SILVEIRINHA, 2005, p. 147), põe-se hoje a necessidade de saber se a «democracia pode respeitar as diferenças, não as marginalizando e tornando-se (...) mais inclusiva» (idem, ibidem). Se «com efeito, o poder por vezes penetra na forma, no estilo e no conteúdo do discurso, o que significa que os grupos mais marginalizados normalmente tendem a ser excluídos ou silenciados» (idem: 24), a questão é saber como lidar com as diferentes formas pelas quais as relações de poder distorcem a deliberação e como compensar a desigual capacidade daqueles que desejam entrar no fórum, nomeadamente as minorias e, neste caso, as vozes de mulheres.

A tecnologia da Internet tem sido vista como potenciadora de um reavivamento da esfera pública que, em simultâneo, promove a participação cívica (DAHLGREN, 2000; KWAK, WILLIAMS, WANG \& LEE, 2005), ao fornecer mais um espaço de expressão política e de debate. Determinadas características como a acessibilidade, interactividade e descentralização (NEGROPONTE, 1998) fundamentam a ideia de que a Internet aumenta a sensibilização para os problemas colectivos, destacando as oportunidades de envolvimento dos diversos públicos e dos cidadãos (DAHLGREN, 2000; KWAK et al., 2005).

Partindo de um enquadramento conceptual e teórico baseado na esfera pública habermasiana, o presente projecto pretende compreender os processos deliberativos e explorar até que ponto a Internet pode promover e potenciar o envolvimento cívico das mulheres. Através de análise de conteúdo e de discurso de uma amostra seleccionada de blogues e fóruns, ao longo de um período definido de tempo, tencionamos inquirir da existência de bases de sustentação empírica que possam comprovar o funcionamento de uma esfera pública dita 'feminina' e mediada através da Internet. 


\section{Para além da esfera pública habermasiana: a exclusão do género e as críticas feministas}

Em The Structural Transformation of the Public Sphere (1989), Habermas define a esfera pública como combinando os conceitos de público e de privado. Se, por um lado, esta esfera é constituída por indivíduos privados, por outro, o seu papel é fundamentalmente público, uma vez que «os indivíduos se reúnem para constituírem uma opinião pública sobre assuntos de interesse geral, através de uma discussão crítica e racional dessas matérias» (SILVA, 2009, p. 10). Para o autor, este é o espaço onde os cidadãos deliberam acerca de assuntos comuns «ou ainda uma arena institucionalizada, distinta do Estado, de interacção discursiva» (Fraser in idem, ibidem). A distinção clara entre Estado e domínio privado, característica da modernidade, destacava neste último uma esfera do privado, composta pela sociedade civil e pela esfera íntima da família conjugal, e uma esfera pública, ou seja, «uma arena de discussão pública entre os indivíduos privados, onde ocorrem as mediações políticas que viriam a constituir as sociedades democráticas» (idem, ibidem). $\mathrm{O}$ Espaço Público começou, portanto, por se assumir como instância exterior ao poder, uma emanação da sociedade civil e autónoma ao Estado, sendo chamado a exercer funções de poder e a participar directamente na própria dominação, em posição, pois, de interioridade face ao Estado (e ao poder)» (idem, ibidem).

As modernas instâncias sociais do Público, o Espaço Público e a Opinião Pública têm na sua génese «uma liberdade "individualista", essencialmente "privada" e que tem na comunicação um pilar fundamental» (ESTEVES, 2003, p.31), realizado através das práticas sociais e simbólicas intrinsecamente associadas ao Espaço Público, a publicidade e a crítica. A publicidade enquanto publicitação, isto é, «acto de tornar público (opiniões, conhecimentos, experiências...) tem, por um lado, uma ligação estreita com a razão (idem: 35), por outro, uma vinculação com a subjectividade (tparte do indivíduo), emergindo historicamente como resultado do processo no qual os indivíduos exigem dos governantes a justificação moral dos seus actos (SILVEIRINHA, 2005, p. 154). A crítica qualifica a comunicação pública moderna como processando uma «espécie de controlo pragmático da verdade dos enunciados produzidos» (ESTEVES, 2003, p. 34). Em termos políticos, seria uma «garantia ética de justiça dos consensos e compromissos obtidos na discussão pública» (idem: 35). Estas duas práticas sociais congregam-se na figura comunicacional do Debate, que é, segundo Cohen (1997), o procedimento político por excelência. 
O conceito de esfera pública habermasiana tem na sua origem algumas características centrais do debate democrático contemporâneo: a ideia de um espaço de interação face-a-face diferenciado do Estado e a discussão em torno do conteúdo moral das diferentes relações sociais. O Espaço Público moderno é também indissociável de um conjunto de critérios formais (ideais) organizadores da comunicação: «livre participação de todos os interessados (...), livre discussão de temas e assuntos (...) e igualdade de estatuto de todos os participantes (...)» (Esteves, 2003, p. 37). Para além desta dimensão ideal - uma comunicação plenamente livre e igualitária - há uma componente de cepticismo que se evidenciou à medida que as ambiguidades comunicacionais evoluíram para formas cada vez mais tensionais e contraditórias (idem, ibidem $)^{5}$.

O modelo habermasiano tem vindo a ser objecto de fortes críticas por parte dos estudos feministas, atacado maioritariamente devido à concepção liberal e unitária que lhe esteve subjacente. O ponto central está no facto de esta esfera ter sido fundada por um número significativo de exclusões - de género, etnia, classe e cultura popular (ÁLVARES, 2009, p. 57). A esfera pública burguesa, fazendo uso das normas da universalidade e da razão com a função mesma de excluir as mulheres (cfr. BAKER in SILVA, 2009, p. 18), era essencialmente masculina ${ }^{6}$ e logocêntrica. Assim, como enuncia Papacharissi (2002) «este auge da democracia foi bastante nãodemocrático na sua estrutura ao longo dos séculos, ao não incluir mulheres ou pessoas de classes sociais mais baixas, um ponto reconhecido pelo próprio Habermas» (idem: 11).

As críticas feministas demonstram a forma como o pensamento político moderno é profundamente marcado pelo género ("gendered") nas suas estruturas (ELEY in SILVA, 2009, p. 19). Assim, «a exclusão das mulheres da vida pública não pode ser entendida como meramente acidental ou circunstancial, mas assume antes um carácter propriamente ideológico» (idem: 18-9). Embora Habermas reconheça o carácter exclusivo e ideológico da esfera pública burguesa, o autor subsumia todas as possibilidades a um único modelo que «não é teórico ou historicamente neutro, mas sim associado com um conjunto específico de interesses de classe e género e que é, na verdade, inacessível à maioria» (MCLAUGHLIN, 1993, p. 604).

Também Seyla Benhabib e Iris Marion Young, partindo de premissas feministas, criticam a

\footnotetext{
${ }^{5}$ A transformação estrutural de que foi alvo o Espaço Público no decurso do desenvolvimento da modernidade contribuiu para acentuar as suas características de processo, em detrimento de uma estrutura (Esteves, 2003, p. 40). Um conjunto de transformações económicas, sociais e políticas congrega os elementos desta crise do Público e do Privado e comporta também «um certo potencial de superação desses mesmos domínios, patente na formação de uma nova "Esfera Social" que não é já verdadeiramente pública nem privada» (Esteves, 2003, p. 42).

${ }^{6}$ Embora permitisse o acesso de algumas mulheres da elite.
} 
forma como as mulheres são marginalizadas da política, a partir, nomeadamente, da própria definição desta "política" «como uma esfera à parte da vida privada que obscurece a forma como as relações de poder se estendem aos dois domínios, actuando assim como uma forma discursiva de poder» (SILVEIRINHA, 2005, p. 160), excluindo o quotidiano, decidindo quem pode aceder ao espaço público, e determinando também o que está aberto a discussão e a própria forma que esta discussão deve assumir. Segundo Benhabib (1992), Habermas e, em geral, a teoria política contemporânea, ignorou o problema das diferenças das experiências dos homens e das mulheres em todos os domínios da vida (in SILVA, 2009, p. 68). Os movimentos feministas mostraram que as formas de distinção entre público e privado fazem parte de um discurso de dominação que legitima a opressão das mulheres e a sua exploração no domínio privado. Ainda assim, para Benhabib, e apesar das suas falhas, o modelo discursivo do espaço público habermasiano é «o único que é compatível com as ambições emancipatórias dos novos movimentos sociais e é o que mais se adequa à teorização da experiência democrática das sociedades complexas, na medida em que a deliberação pretende ser uma forma de atrair as margens da sociedade» (in idem: 69).

Contrariamente à ideia de uma única esfera pública, diversos autores defendem a existência simultânea de espaços públicos múltiplos e por vezes opostos. Nancy Fraser avança com a proposta de um Espaço Público que seja uma política de «arenas discursivas paralelas onde todos os membros de grupos sociais subordinados inventam e circulam contra-discursos para formular interpretações oposicionais às suas identidades, interesses e necessidades» (in Silveirinha, 2005, p. 155). A constituição de públicos alternativos e de arenas discursivas paralelas, permite a formação de contra-discursos e a formulação de interpretações alternativas sobre as identidades, interesses e necessidades dos «membros de grupos oprimidos, subordinados ou marginalizados - mulheres, trabalhadores, imigrantes, pessoas de cor, pessoas sem casa, lésbicas e gays - que formam espaços discursivos alternativos com o objectivo de promover solidariedade de grupo e desafiar relações sociais, políticas e económicas de dominação» (HOWLEY, in DEVEREUX, 2007, p. 342). Para Fraser, «as formações que contemplem a contestação entre a pluralidade de públicos concorrentes promovem melhor o ideal de paridade de participação do que um espaço público único, compreensivo, abrangente» (in SILVEIRINHA, 2005, p. 176). Surgindo como resposta a exclusões por parte dos públicos dominantes, estes contra-públicos ajudam a expandir o espaço discursivo, tendo portanto um potencial emancipatório (mas não o garantindo por si só).

O espaço online permite precisamente a coexistência destas diversas formas de discurso, que 
vão além de uma comunicação racional-crítica-argumentativa (ESTEVES, 2003, p. 202). Esta acessibilidade proporciona maneiras diferentes de pensar os assuntos públicos dando forma a «um outro tipo de Espaço Público: não homogéneo, mais multifacetado, que inclui esferas públicas oficiais (governativas), massmediadas, de contra-públicos, informais, etc., muitas vezes com relações tensionais entre si» (in ESTEVES, 2003, p. 203). Desta maneira, o padrão dominante (racional-argumentativo) passa a coexistir com outras formas de linguagem - como por exemplo, aquelas que se encontram mais ligadas às emoções e sentimentos (ESTEVES, 2003, p. 204), possibilitando, nas palavras de Young, a afirmação de uma nova «concepção da razão normativa que não oponha a razão à afectividade e ao desejo» (in ESTEVES, 2003, p. 204). Neste contexto, também o conceito de política se abre para novos sentidos, cobrindo um conjunto vasto de assuntos que, segundo Ranerup (1999), podem ir desde questões econômicas ou ambientais a assuntos relativos à sociedade em geral, ao trânsito ou ao cuidado de crianças» (in TSALIKI, 2002, p. 100).

\section{Deliberação, diferença e participação online}

A participação dos cidadãos é não só considerada uma das fundações da democracia (HABERMAS, 1989), mas também um processo fundamental na promoção de uma melhor cidadania (GASTIL, 2000). A democracia deliberativa coloca a tónica no cidadão como actor político (SILVEIRINHA, 2005, p. 151), agente autónomo que participa no processo político (cfr. GUTMANN et al. in SILVA, 2009, p. 49) e considera a diferença como objecto de deliberação. Segundo Dryzek (2000), «a deliberação, por definição, especifica que os indivíduos comuniquem, relativamente às decisões colectivas, em termos que possibilitem uma aceitação reflexiva por parte dos que ficam sujeitos à decisão» (in SILVEIRINHA, 2005, p. 151). Assim, o enfoque está na ideia de que as diferenças de opinião entre participantes deveriam manifestar-se através de uma livre troca de argumentos que conduziria, em última instância, a um consenso e à influência no processo de tomada de decisão.

A teoria da ação comunicativa habermasiana procura dar resposta à forma através da qual o público pode desenvolver processos críticos de comunicação (HABERMAS in SILVA, 2009, p. 20). Precisamente, «quando os atores se dirigem uns aos outros com o objetivo de alcançar o entendimento» (para o autor, o verdadeiro telos do discurso), engajam naquilo que Habermas designa de acção comunicativa (BOHMAN e REHG, 2007). A definição de racionalidade, enquanto epistémica, prática e intersubjectiva, consiste na forma como estes «sujeitos falantes e actuantes 
adquirem e usam conhecimento» (HABERMAS, 1984). O ato do discurso implica a existência de razões que sustentem um dado pressuposto - sujeito tanto à crítica como à justificação (BOHMAN e REHG, 2007). Os pressupostos nos processos de argumentação e diálogo devem ser testados quanto à sua justicação racional como sendo verdadeiros, correctos ou autênticos. Haverá portanto uma pretensão de que o discurso seja sincero (não-enganador), socialmente apropriado ou correcto e factualmente verdadeiro (BOHMAN e REHG, 2007). ${ }^{7}$

Habermas propõe assim uma concepção de razão que é multidimensional: as formas de validade cognitiva são também «pressupostos de rectidão (...), afirmações de autenticidade sobre a vida boa, afirmações técnico-pragmáticas sobre os meios que podem servir diferentes objectivos» (BOHMAN e REHG, 2007). É quando estas pretensões de validade são problematizadas que ocorre a passagem da acção comunicativa para o discurso, que implica que o falante faça uso de argumentos para justificar as suas asserções.

No entanto, a capacidade de argumentação, que nos termos habermasianos deve conduzir ao melhor argumento, não se encontra distribuída de uma forma uniforme por toda a gente (SILVEIRINHA, 2005, p. 165). Exactamente por esta razão, a democracia deliberativa necessita de incorporar um alcance mais vasto de formas de comunicação a fim de poder incluir todos os grupos sociais e culturais, «diferenciados na sua forma e no seu acesso ao poder» (SILVEIRINHA, 2005, p. 165). Com efeito, o poder penetra na forma, no estilo e no conteúdo do discurso, o que significa que os grupos marginalizados normalmente tendem a ser excluídos ou silenciados. As teorizações feministas têm, segundo Iris Young (1996) vindo a demonstrar que «as raparigas e as mulheres tendem a falar menos que os rapazes e os homens em situações de discurso que valorizam a afirmação e o confronto de argumentos» (in SILVEIRINHA, 2005, p. 165). Para contrariar esta tendência, torna-se então necessário «um igual privilegiar de qualquer forma de interacção comunicativa onde as pessoas procuram alcançar entendimento» (SILVEIRINHA, 2005, p. 165).

Iris Young que pensa um modelo de democracia deliberativa que destaca precisamente a possibilidade de comunicar a diferença (SILVEIRINHA, 2005, p. 161). Para que o espaço seja aberto e público, isto é, verdadeiramente acessível e assim normativamente legítimo, é necessário

7 Habermas não limita as «validity claims» ou pretensões de validade justificáveis à categoria da verdade empírica (Bohman e Rehg, 2007), incluindo pretensões à rectidão ou justiça moral, ética ou autenticidade, sinceridade pessoal e valor estético (Habermas, in idem). A pretensão de validade conota assim um sentido mais alargado ao ser «merecedora da aceitação do interlocutor porque é justificada ou verdadeira nalgum sentido, que pode variar de acordo com a esfera de validade e o contexto dialógico» (idem). 
combater todas as formas pelas quais a inclusão é impedida (idem: 163), passando a incluir-se a representação e a participação directa dos grupos sociais em desvantagem. Em causa está, afinal, a necessidade de «uma concepção vasta e plural de comunicação que inclua a expressão e extensão de compreensões partilhadas onde elas existem, e o oferecimento e reconhecimento de significados não partilhados» (YOUNG in SILVEIRINHA, 2005, p. 133).

A principal condição de realização da democracia reside em decisões assentes numa discussão argumentada aberta a todos os pontos de vista e orientada para a produção de um acordo, a partir de procedimentos de troca de razões sobre o que é justo (SILVEIRINHA, 2005, p. 157). A multiplicidade de «espaços públicos, de carácter mais informal e de estrutura anárquica, têm como principal desvantagem, em relação aos espaços públicos formais e organizados, uma maior exposição aos efeitos de repressão e de exclusão que resultam da distribuição desigual do poder social. No entanto, essa mesma estrutura anárquica e mais espontânea possibilita uma comunicação mais livre, sem tantos constrangimentos, onde os novos problemas, os discursos de autoentendimento e as interpretações das necessidades se compreendem, efectuam e articulam» (SILVA, 2009, p. 56). É precisamente este o potencial que o ciberespaço parece oferecer, uma vez que o sucesso da política deliberativa depende destes espaços públicos não-institucionalizados, «que têm a função fundamental de agir dentro do "contexto da descoberta", ou seja, detectar e tematizar problemas que requerem depois tratamento pelo sistema político formal» ( FLYNN in SILVA, 2009, p. 56).

De acordo com Dahlberg (2001), três campos emergiram dentro das retóricas e práticas de experimentação da democracia online: «um campo comunitário, que destaca a possibilidade da Internet promover o espírito e valores comunitários. (...) um campo liberal individualista, que vê a Internet como auxiliando a expressão dos interesses individuais. (...) um campo deliberativo, que promove a Internet como meio de expansão da esfera pública» (idem: 616). Apesar do controlo dos interesses corporativos e da comercialização do meio da Internet, «uma enorme quantidade de discurso tem lugar online relativamente autónoma do estado e questões económicas» (idem: 617). Ou seja, segundo este autor, a comunicação descentralizada proporcionada pela publicação na web, mailing-lists, chat-rooms, blogues e fóruns providencia espaços públicos para um discurso críticoracional (idem: 616). No entanto, o resultado pode ser uma fragmentação do discurso em comunidades mutuamente exclusivas, uma vez que muitos participantes procuram simplesmente discutir em grupos de partilha de interesses, onde valores e preconceitos são reforçados em vez de 
desafiados (idem: 618).

Uma série de características ajuda a pensar a possibilidade do discurso online estender ou expandir a esfera pública: «troca e crítica de pretensões de validade prático-morais fundamentadas (...); reflexividade: os participantes devem examinar criticamente os seus valores culturais, pressupostos e interesses, bem como o contexto social mais amplo»; «tomada de papel ideal: os participantes devem procurar entender o argumento a partir da perspectiva do outro (...); «sinceridade: cada participante deve fazer um esforço para fornecer toda a informação relevante para o problema particular em consideração, incluindo informação relativa a intenções, interesses, necessidades e desejos»; «inclusão e igualdade discursiva: todos os participantes afectados pelas pretensões de validade em consideração têm igualmente direito a introduzir e questionar cada afirmação»; «autonomia do estado e do poder económico: o discurso deve ser conduzido pelas preocupações públicas dos cidadãos em vez pelo poder e dinheiro administrativo» (DAHLBERG 2001, p. 622-23).

Como destaca Bohman (1997), o diálogo com os outros exige capacidades consideráveis de cognição e comunicação, mas a política deliberativa não pode, no espírito democrático, «simplesmente favorecer aqueles que são mais educados, que têm acesso a informação especial, que possuem os maiores recursos e posições sociais privilegiadas» (in SILVA, 2009, p. 59). É nesta linha que Carol Gould (1996) considera que «a maior esperança para a representação da diferença tanto individual como de grupo - dentro de uma política democrática, é a expansão de oportunidades de participação numa diversidade de actividades comuns (...). Nestes contextos, a diferença pode ser directamente expressa, reconhecida e tornada efectiva» (in SILVEIRINHA, 2005, p. 175). É portanto necessária a «integração dos discursos informais e da linguagem dos que têm menos recursos linguísticos, mas também dos que têm menos recursos sociais, económicos e políticos, nas estruturas de decisão» (SILVEIRINHA, 2005, p. 176), como também defende Nancy Fraser.

Comum a estas propostas é a convicção de que as lutas de identidade apenas possuem força de legitimação na medida em que todos os grupos possam ter acesso ao espaço público político para fazer ouvir a sua voz e articular as suas necessidades. Isso passa, naturalmente, por um lado pela sua representação, isto é, por assegurar as condições reais de uma utilização dos direitos formalmente iguais que ofereçam uma verdadeira igualdade de oportunidades ao nível público, mas também por encontrar formas comunicativas que não se centrem exclusivamente na questão do argumento, por 
considerar a deliberação não apenas como o processo que visa o bem comum, mas como aquele que ajuda os participantes a clarificar os seus interesses (SILVEIRINHA, 2005, p. 174-5).

\section{Possibilidades de expansão e revitalização da esfera pública online}

É precisamente neste contexto que alguns autores falam da possibilidade de revitalização da esfera pública através do ciberespaço. imaginado como lugar onde os 'netizens' ${ }^{8}$ poderiam discutir diversos assuntos e influenciar a tomada de decisão política (HURWITZ, in JENKINS, 2004, p. 101). Desta forma, à medida que a Internet se foi tornando um centro de poder, conferiu também uma nova identidade sociopolítica aos seus utilizadores (idem: ibidem), num espaço que é simultaneamente público e privado (PAPACHARISSI, 2002, p. 20).

A capacidade da Internet para levar e transportar informação e o seu potencial para reunir num mesmo espaço virtual pessoas com diferentes backgrounds permitiu, de acordo com Papacharissi (2002), efectivamente, criar um novo espaço público para conversações politicamente orientadas (idem, 12). O ciberespaço pode ser uma possibilidade para «uma esfera pública que nunca existiu, promover várias e diversas esferas públicas ou simplesmente ser absorvida pela cultura comercial» (idem: ibidem). Um novo espaço público, não é portanto, como destaca esta autora, sinónimo de uma nova Esfera Pública (idem: 11): «Como Espaço Público, a Internet providencia mais um fórum de deliberação política. Enquanto Esfera Pública, a Internet pode facilitar discussão que promova uma troca democrática de ideias e opiniões. Um espaço virtual estimula a discussão; uma esfera virtual estimula a democracia» (idem: ibidem). Assim, embora providencie espaço adicional, o ciberespaço não deixa de estar «atormentado pelas inadequações do nosso sistema político» (idem: ibidem). Por exemplo, Susan Herring (1996) argumenta que há um domínio dos homens no ciberespaço: «falam mais, orientam as escolhas de tópicos, e o seu estilo de comunicação foi codificado em regras de etiqueta na Internet (Netiquette)» (in SILVEIRINHA, 2004: 263). Vemos assim, que as desvantagens sofridas pelas mulheres na sociedade podem passar para as comunidades virtuais, através da sua possível sub-representação (POSTER, 1995).

Mas se o espaço público surge como arena de relações sociais e políticas, onde as identidades colectivas e individuais se constituem e integram (SILVEIRINHA, 2004, p. 251), neste sentido, a comunicação electrónica é um medium que muda radicalmente a própria situação social (MEYROWITZ in SILVEIRINHA, 2004, p. 254). Deste modo, «a identidade social, aquilo que nós

8 Neologismo formado pelos termos Internet e citizen (cidadãos) para referir o utilizador da Internet. 
somos socialmente, para nós e para os outros, não reside em nós próprios, mas numa rede de relações sociais» (SILVEIRINHA, 2004, p. 254). O ciberespaço, enquanto domínio público gerado por computador, que não tem fronteiras territoriais ou atributos físicos (SILVEIRINHA, 2004, p. 257), permite explorar conceitos como «novos sentidos de comunidade e transcendência das subjugações físicas da identidade» (SILVEIRINHA, 2004, p. 257). Poster (1995) designa esta a "segunda era dos media", que instaura uma compreensão do sujeito totalmente nova, assente no modo da informação (essencialmente, na forma de comunicação mediada por computador) e na pósmodernidade

o modo de informação põe em marcha uma radical configuração da linguagem, constituindo os sujeitos fora do esquema do indivíduo autónomo e racional. Este sujeito moderno familiar é deslocado pelo modo da informação em favor de um sujeito múltiplo, disseminado e descentrado, continuamente interpelado com uma identidade instável. (POSTER in SILVEIRINHA, 2004, p. 257).

Os lugares desta nova sociabilidade são os grupos de discussão, onde as possibilidades de experimentação com a identidade se desenvolvem com potencialidades de troca de género, de raça, de idade, etc. Estes fóruns públicos «devem existir para que a deliberação democrática online seja livre do estado e do controlo corporativo. Um fórum aberto conformar-se-ia teoricamente às condições discursivas ideais para uma esfera pública crítica-racional» (in TSALIKI, 2002, p. 98).

$\mathrm{O}$ anonimato online permite a obliteração das identidades reais e potencia uma comunicação mais livre e aberta (PAPACHARISSI, 2004, p. 266). Ao entrar numa comunidade virtual, o indivíduo apresenta-se com o nome que lhe aprouver e com as informações que quiser dar de si, permitindo-lhe reinventar-se. Assim, «o que pode ficar de fora da "apresentação do Eu", neste contexto, são todos os atributos "não-escolhidos" do sujeito: a sua raça, o seu género, a sua identidade, enfim, todas as características físicas» (SILVEIRINHA, 2004, p. 261). Daqui resulta uma maior flexibilidade do sujeito, «na sua capacidade de incluir dimensões diferentes e mesmo contraditórias» (idem: 261), o que sugere a possibilidade de uma comunicação menos constrangida. Esta possibilidade de (re)construção constante das identidades, denota, segundo Poster (1995), «uma "democratização" da constituição do sujeito porque os actos discursivos não estão limitados a uma comunicação unidireccional e não estão constrangidos pelo género e traços étnicos inscritos nas comunicações face-a-face». Este meio é capaz, assim, de introduzir uma radicalidade, por ser uma «tecnologia que põe os actos culturais, simbolizações em todas as formas, nas mãos de todos os participantes; [e] descentraliza radicalmente as posições do discurso (...) e dos aparatos de 
produção cultural» (POSTER, 1995). Também as próprias condições de comunicação nas comunidades online introduzem resistências e rupturas com as determinações de género: «o facto de se ter de decidir o género em si levanta desde logo a questão da identidade individual de uma maneira nova e convincente. Se alguém é masculino, tem que escolher sê-lo» (idem). Isto tem duas implicações: netizen não pode confundir-se com citizen; e se o facto de se pertencer a um determinado género, ou uma determinada etnia, filiação política, etc., não está imediatamente representado ou apresentado, essa característica não está ausente na sua totalidade. Efectivamente, na sua forma mais visível, a um cidadão não corresponde necessariamente um único netizen mas sim uma potencial multiplicidade deles. A tomada de decisões democráticas está interdependente da contagem de cidadãos que se fazem representar - essa tarefa é extremamente mais difícil de levar a cabo online. No que toca à segunda implicação: a ausência de marcas directas de sexo, género, etnia ou condição sócio-cultural revela todos estes factores identitários como performativos, mas não impede que a biografia do sujeito aja sobre a forma como este escolhe representar-se. O controlo que o sujeito tem sobre as suas representações nunca é total e absoluto, na medida em que o sujeito não pode, in extremis, prestar totalmente contas sobre si mesmo (BUTLER, 2005). Além disso, o género tem, neste meio, que ser representado quase exclusivamente através da linguagem, através, portanto de meios principalmente textuais. Simultaneamente, a própria fluidez e mobilidade das identidades online torna mais difícil o comprometimento dos utilizadores, resultando numa comunicação descentralizada, potenciada pela característica de fragmentação deste meio (SILVEIRINHA, 2004, p. 262). Há efectivamente uma segmentação em torno de grupos de interesse, embora se possa pertencer, transversalmente, a mais que uma comunidade: «a identidade torna-se então o limite da distância de alguém comprometendo a própria acção colectiva» (WILSON, 1997).

Como diz Ess (1997), a comunicação mediada por computador funciona como uma extensão da interacção quotidiana e não como sua alternativa (in SILVEIRINHA, 2004, p. 269), constituindose como um medium ideal para o desenvolvimento da razão comunicativa (idem: 270). Assim, «a racionalidade emerge através da prática online, apesar da fragmentação do self que tem lugar no ciberespaço» (TSALIKI, 2002, p. 98). Esta racionalidade é, portanto, construída discursivamente, desenvolvida no processo da interacção online (idem: ibidem). Esta ideia harmoniza-se com a concepção habermasiana de uma esfera pública em que os sujeitos desenvolvem autonomia e reflexividade através da deliberação (in idem: 98), mas não já numa esfera única e centralizada. 
Apesar destas possibilidades existirem, não é certo que o ciberespaço seja, na prática, capaz de neutralizar o género (BOUDOURIDES e DRAKOU, 2000). Na comunicação mediada por computador o género (bem como a raça e a classe social, entre outros) tinha vindo a ser considerado como invisível quando exclusivamente textual, uma ideia reforçada, como já vimos, pela ausência de características físicas que evidenciem a identidade dos utilizadores, tornando portanto o meio online inerentemente democrático e igualitário (HERRING, 2000). No entanto, estas afirmações não foram confirmadas pela pesquisa sobre as interacções online (idem). Segundo estes estudos há, pois, uma assimetria de género que persiste também num espaço público virtual, e que coloca as mulheres em diferentes papéis redutores, desde «participantes menores» da discussão, até «objectos sexuais» (HERRING, 2000). Torna-se, deste modo, não só necessário compreender estas mecânicas (e verificar se ainda se aplicam e como) e indispensável a existência e desenvolvimento de uma dimensão ética, uma vez que, «numa interacção dominada de novo pela "conversação", pelo contacto pessoa-a-pessoa, pela partilha de interesses privados, não é certo que se gira um "bemcomum" (...) ou que a identidade "jogada" nessa interação tenha continuidade no off-line» (SILVEIRINHA, 2004, p. 263-4).

De resto, o próprio conceito de comunidade precisa de ser profundamente revisto. Jan Fernback (2007) aponta o uso da palavra "comunidade" como sendo excessivo, e fundamentalmente diluído. O uso pouco cuidado da palavra transformou-a, segundo este autor, num conceito «descritivo e prescritivo, local e global, espacialmente definido ou indefinível, público ou privado, orgânico ou mecânico, intencional ou acidental, teleológico ou sem objetivos, opressivo ou libertador, funcional ou disfuncional» (idem: 52) - retratando o espaço online como uma zona onde dificilmente seria possível realizar os ideais políticos habermasianos. Maria Bakardjieva (2003) postula uma posição diferente. Apesar de também esta autora considerar importante um repensar do uso da palavra "comunidade", ela vê no online a possibilidade de surgimento da emergência de «novas formas sociais» (idem: 294). A autora critica também a polarização comummente praticada nas ciências sociais em torno desta questão: real versus virtual, espaço público versus espaço privado. Segundo Bakardjieva, há espaço, no contexto online, para experiências que fundem e reformulam estas concepções. Barry Wellman (um dos autores em quem Bakardjieva se inspira na sua crítica) define comunidade como um conjunto de «redes de laços interpessoais que fornecem sociabilidade, apoio, informação, sentimento de pertença e identidade social» (WELLMAN, 2001, p. 228). O mesmo não será dizer que a noção de comunidade está, por este meio, automaticamente 
revitalizada. Wellman faz uma análise de diferentes tipos de comunidade, começando pela noção típica de comunidade (que é também uma noção com afinidades com o espaço público) proximidade física e psicológica, identitária; avança depois para as "little boxes" - pequenas caixas de pessoas conhecidas que já estão distantes fisicamente, mas que partilham características; por fim, o modo comunitário próprio da Internet - as redes personalizadas, ou individualizadas, que são a base do individualismo em rede. A unidade de base destas redes é o indivíduo (WELLMAN, 2001), e não o grupo ou o lar. A localização física torna-se, desta forma, irrelevante.

Isto não representa uma validação total dos argumentos de Fernback - antes, uma forma diferente de criar comunidade, que chama a atenção para um tratamento específico das formas de socialização em jogo no espaço cibernético. A base visual da metáfora filosófica ajuda a compreender esta questão. Enquanto que o espaço público habermasiano é uma zona que necessita de ser preenchida por seres racionais que debatem de acordo com princípios ideais, o funcionamento da Internet opera de acordo com uma outra estrutura - a estrutura da rede, enquanto conjunto de traços bidimensionais que se cruzam e encontram. Esses traços reticulares são, mutatis mutandis, as vias de acesso e, ao mesmo tempo, as práticas levadas a cabo online. O cruzamento de vários traços - sejam eles participativos ou passivos, com maior ou menor anonimato ou voyeurismo - geram e são os “espaços” da virtualidade. São esses nódulos criados pelo entrelaçar de várias linhas que irão ser abordados neste projecto - e como o género se articula nestes nexos discursivos. Essas linhas são compostas por individualidades que, independentemente de exporem ou não os seus nomes, géneros, sexos ou etnias, trazem para o primeiro plano as diferenças e as subjetividades, possibilitando e talvez privilegiando uma componente contemporânea do sujeito político, até então ausente: a intimidade.

Segundo Ken Plummer (1995), a intimidade transformou-se num outro componente do cidadão, que se junta às clássicas (política, legal e de bem-estar [welfare]). Os debates sobre o corpo, sobre a orientação sexual, sobre o aborto, sobre o casamento, sobre a adopção, etc., são debates a um tempo políticos no sentido clássico do termo, mas também debates com o forte cunho da intimidade, trazidos ao espaço público. Aqui, para o mesmo autor, o papel dos movimentos feministas tem sido fundamental, ao apresentar narrativas alternativas que podem ser utilizadas pelos indivíduos (idem: 157, 158, 165), seja online seja offline. Isto porque mesmo as representações alternativas necessitam de um horizonte de legibilidade - as narrativas criadas por estes movimentos (por estas comunidades também), ou as tornadas possíveis por eles - que, 
necessariamente, condicionará as representações possíveis e significativas.

Parecendo seguir esta linha, as características da Internet parecem apresentar uma comunicação «aparentemente mais personalizada, mais próxima, menos anónima, menos massmediada (...) e sobretudo com um maior potencial de interactividade» (SILVEIRINHA, 2004, p. 266). Assim:

Aparentemente, quebra-se (...) a comunicação dos media tradicionais, uma comunicação dirigida num só sentido, em que os receptores pouca ou nenhuma capacidade tinham de resposta (...). Os novos media surgem como a superação das suas formas anteriores, numa modalidade superior e mais eficaz, permitindo uma nova relação entre indivíduos e comunidades, e entre estas e a política. (SILVEIRINHA, 2004, p. 266).

Se para Habermas a lógica e a razão promovem o discurso e devem guiar uma sociedade democrática (in Papacharissi, 2004, p. 266), alguns autores consideram que na Internet a discussão política é frequentemente anárquica (PAPACHARISSI, 2004, p. 260). É precisamente esta característica de um certo anarquismo que nos leva de encontro à visão de democracia de Lyotard (1984). Para este autor, são a anarquia, individualidade e desacordo, em vez do acordo racional, que conduzem à verdadeira emancipação democrática (in PAPACHARISSI, 2004, p. 266). Como a ausência da comunicação face-a-face promove uma discussão potencialmente mais acalorada, poderemos considerar que o ciberespaço promove esta visão democrática, de emancipação através do desacordo (idem: ibidem)

No entanto a visão das comunidades virtuais não é unilateral, havendo diversos autores que defendem que a comunicação online se pode tornar uma experiência alienante, de desenraizamento espacial e temporal, que desenvolve interesses funcionais limitados. Estas preocupações, bem como questões relativas ao acesso à comunicação mediada por computador, encontram-se portanto do lado de uma visão distópica das novas tecnologias e suas potencialidades, que este projecto pretende avaliar também no contexto em análise. Mesmo tendo em conta estas características, um facto é que a comunicação muitos-a-muitos (por oposição aos meios tradicionais em que a comunicação é feita de um para muitos) apresenta «uma aparente grande capacidade de retroacção» (SILVEIRINHA, 2004, p. 267). A Internet surge assim como «um novo medium onde novas vozes, individuais e em grupo, podem ser ouvidas e vistas por uma rede que ultrapassa as fronteiras convencionais dos sistemas mediáticos» (idem: ibidem). O que nos propomos a auscultar é precisamente a concretização ou não destas potencialidades num espaço online selecionado entre 
fóruns e blogs de língua portuguesa e também internacionais. Questionar que tipo de vozes adquirem, conquistam e utilizam as pessoas que se identificam, na Internet, com o gênero feminino, e de que formas negoceiam os desafios que se lhes apresentam neste meio de comunicação, de que forma o utilizam e se fazem representar para agir, sempre politicamente, de forma a melhorar as suas próprias condições de existência - em última análise, as condições de existência da Internet e do espaço sócio-político geral.

\section{Referências}

ADAM, A. Computer ethics in a different voice. Information and organization, v. 11, n. 4, p. 235261, 2001.

ÁLVARES, C. Ética feminista e a interrogação do espaço público universalista. Revista Media \& Jornalismo, v. 8, n. 15, p.55-68, 2010.

ASEN, R. Seeking the Counter. In: Counterpublics. Communication theory, v. 10, n. 4, p. 424446, 2000.

BAKARDJIEVA, M. Virtual Togetherness: an everyday-life perspective. Media culture society, v. 25, n. 3, p. 291-313, 2003.

BENHABIB, S. Democracy and difference: contesting the boundaries of the political. Princeton University Press, 1996.

BRANDENBURG, H. Pathologies of the virtual public sphere. The European consortium for political research. [S.1.: s.n.], 2003.

BRUNDIDGE, J. Encountering Difference. In the Contemporary Public Sphere: the contribution of the internet to the heterogeneity of political discussion networks. Journal of Communication, $v$. 60, n. 4, p. 680-700, 2010.

BUTLER, J. Giving an account of oneself. Fordham Univ. Press, 2005.

CHANG, L.; JACOBSON, T. Measuring participation as communicative action: a case study of citizen involvement in and assessment of a city's smoking cessation policy-making process.

Journal of Communication, v. 60, n. 4, p. 660-679, 2010.

CHARNEY, E. Political liberalism: deliberative democracy and the public sphere. The American

Political Science Review, v. 92, n. 1, p. 97-110, 1998.

DAHLBERG, L. The Internet and democratic discourse: exploring the prospects of online deliberative forums extending the public sphere. Information, Communication \& Society, v. 4, n. 4, p. 615-633, 2001.

DAHLGREN, P. The Internet, public spheres, and political communication: dispersion and deliberation. Political Communication, v. 22, n. 2, p. 147, 2005.

DIETEL-MCLAUGHLIN, E. Remediating Democracy: irreverent composition and the vernacular rhetorics of Web 2.0. Disponível em: <http://www.bgsu.edu/cconline/Dietel/index.html>. Acesso em: 22 nov. 2010.

DIMAGGIO, P.; HARGITTAI, E.; NEUMAN, W. R.; ROBINSON, J. P. Social Implications of the Internet. Annual Review of Sociology, v. 27, p. 307-336, 2001.

ESTEVES, J. J. P. N. Espaço público e democracia. Editora Unisinos, 2003.

FERNBACK, J. Beyond the diluted community concept: a symbolic interactionist perspective on 
online social relations. New Media Society, v. 9, n. 1, p. 49-69, 2007.

FERREE, M. M.; GAMSON, W. A.; GERHARDS, J.; RUCHT, D. Four models of the public sphere in modern democracies. Theory and Society, v. 31, n. 3, p. 289-324, 2002.

FRASER, N. Justice interruptus: critical reflections on the postsocialist condition. [S. 1.]:

Routledge, 1997.

FRASER, N. Rethinking the public sphere: a contribution to the critique of actually existing democracy. Social text, p. 56-80, 1990.

FRASER, N. Unruly practices: power, discourse and gender in contemporary social theory. Polity Press, 1990.

FROOMKIN, A. M. Habermas@ discourse. Net: toward a critical theory of cyberspace. Harv. L.

Rev., v. 116, p. 749-2709, 2003.

GAJJALA, R. An interrupted postcolonial/feminist cyber ethnography: Complicity and Resistance in the "Cyberfield". Feminist Media Studies, v. 2, n. 2, p. 177, 2002.

GARCIA-BLANCO, I.; BAUWEL, S. V.; CAMMAERTS, B. Media agoras. Cambridge Scholars Pub, 2009.

GARNHAM, N.; CALHOUN, C. Habermas and the public sphere. Global Media and

Communication, v. 3, n. 2, p. 201-214, 2007.

GLE, N. The gendered nature of the public sphere. Public Culture, v. 10, n. 1, p. 61, 1997.

HABERMAS, J. Legitimation crisis. Beacon Press, 1975.

HABERMAS, J. The structural transformation of the public sphere: an inquiry into a category of bourgeois society. Polity Press, 1989.

HABERMAS, J. The theory of communicative action. Beacon Press, 1984.

HABERMAS, J.; FULTNER, B. Truth and justification. MIT Press, 2003.

HABERMAS, J.; HABERMAS, J.; CRONIN, C. P. Justification and Application. MIT Press, 1994.

HABERMAS, J.; REHG, W. Between facts and norms: contributions to a discourse theory of law and democracy. MIT Press, 1998.

HENG, M. S. H.; DE MOOR, A. From habermas communicative theory to practice on the internet. Information Systems Journal, v. 13, n. 4, p. 331-352, 2003.

HERRING, S. C. Computer-mediated discourse. The handbook of discourse analysis, p. 612-634, 2001.

HERRING, S. C. Gender and power in online communication. The handbook of language and gender, pp. 202-228, 2003.

HERRING, S. C.; KOUPER, I.; PAOLILLO, J. C.; ET AL. Conversations in the blogosphere: A social network analysis "from the bottom up". Proceedings of the Thirty-eighth Hawaii

International Conference on System Sciences (HICSS-38). Los Alamitos, CA: IEEE Press. 2005. HERRING, S. C.; PAOLILLO, J. C. Gender and genre variation in weblogs. Journal of Sociolinguistics, v. 10, n. 4, p. 439-459, 2006.

HERRING, S. C.; SCHEIDT, L. A.; BONUS, S.; WRIGHT, E. Bridging the gap: A genre analysis of weblogs. In: System Sciences, 2004. Proceedings of the 37th Annual Hawaii International Conference on. Anais... . p.11, 2004.

HERRING, S. C.; SCHEIDT, L. A.; WRIGHT, E.; BONUS, S. Weblogs as a bridging genre.

Information Technology \& People, v. 18, n. 2, p. 142-171, 2005.

HURWITZ, R. Who needs politics? Who needs people? The ironies of democracy in cyberspace.

Contemporary Sociology, v. 28, n. 6, p. 655-661, 1999.

ISHIDA, T.; ISBISTER, K. (EDS.). Digital Cities. Berlin: Heidelberg, 2000. 
JANSSEN, D. [KIES, R.; L [2]. Online forums and deliberative democracy. Acta Politica, v. 40, p. 317-335, 2005.

KAPLAN, B.; TRUEX, D. P.; WASTELL, D.; WOOD-HARPER, A. T.; DEGROSS, J. I. (Eds.).

Information Systems Research. Boston: Kluwer Academic Publishers, 2004.

KINGWELL, M. A civil tongue. Penn State Press, 1995.

MARQUES, Â. C. S.; MAIA, R. C. M. Everyday conversation in the deliberative process: an analysis of communicative exchanges in discussion groups and their contributions to civic and political socialization. Journal of Communication, v. 60, n. 4, p. 611-635, 2010.

MCCORMICK, N.; LEONARD, J. Gender and sexuality in the cyberspace frontier. Women \& Therapy, v. 19, n. 4, p. 109, 1996.

MCLAUGHLIN, L. Feminism, the public sphere, media and democracy. Media, Culture \& Society, v. 15, n. 4, p. 599, 1993.

MORAHAN-MARTIN, J. Women and girls last: females and the internet. Technology, v. 6, p. 410422.

MORRISETT, L. Technologies of freedom? Democracy and new media. MIT Press. Cambridge: Mass, 2003. p. 21-31.

NATHANIEL POOR. Mechanisms of an online public sphere: the website slashdot. Journal of Computer - Mediated Communication, 2005. Disponível em: <http://jcmc.indiana.edu/vol10/ issue2/poor.html>. Acesso em: 11 set. 2010.

PAPACHARISSI, Z. Democracy online: civility, politeness, and the democratic potential of online political discussion groups. New Media \& Society, v. 6, n. 2, p. 259, 2004.

PAPACHARISSI, Z. The virtual sphere: the internet as a public sphere. New Media \& Society, v. 4, n. 1, p. 9, 2002.

PLUMMER, K. Telling sexual stories. Routledge, 1994.

POSTER, M. Cyberdemocracy: internet and the public sphere. Reading digital culture, p. 259271, 2001.

RASMUSSEN, T. Two faces of the public sphere: the significance of internet communication in public deliberation. Nordicom Review. University of Gothenburg.

REAGLE, J. A case of mutual aid: wikipedia, politeness, and perspective taking. Disponível em: <http://reagle.org/joseph/2004/agree/wikip-agree.html>. Acesso em: 25 out. 2010.

RENDALL, J. Women and the public sphere. Gender. History, v. 11, n. 3, p. 475-488, 1999.

Disponível em: <html_ent glyph="@amp;" ascii="\&amp;"/>.

SAVICKI, V.; KELLEY, M.; OESTERREICH, E. Judgments of gender in computer-mediated communication. Computers in human behavior, v. 15, n. 2, p. 185-194, 1999.

SCHAU, H. J.; GILLY, M. C. We are what we post?: self-presentation in personal web space.

Journal of Consumer Research, v. 30, n. 3, p. 385-404, 2003.

SILVEIRINHA, M. J. Democracia deliberativa e reconhecimento: repensar o espaço público. E POLÍTICA, p. 147.

SILVEIRINHA, M. J. Identidades, media e política. Livros Horizonte, 2004.

TSALIKI, L. Online forums and the enlargement of public space: research findings from a

European project. JAVNOST-LJUBLJANA, v. 9, n. 2, p. 95-112, 2002.

WELLMAN, B. Physical place and cyberplace: the rise of personalized networking. International Journal of Urban and Regional Research, v. 25, n. 2, p. 227-252, 2001.

WELLMAN, I. B. Little boxes, glocalization, and networked individualism. DIGITAL CITIES 2.: COMPUTATIONAL AND SOCIOLOGICAL APPROACHES, p. 10-25, 2002.

WILHELM, A. G. Virtual sounding boards: how deliberative is on-line political discussion? 
Information, Communication \& Society, v. 1, n. 3, p. 313, 1998.

WITSCHGE, T. Online deliberation: possibilities of the internet for deliberative democracy. Democracy online: the prospects for political renewal through the internet. p. 109-122, 2004.

YOUNG, I. M. Inclusion and democracy. Oxford University Press, 2002.

YOUNG, I. M. Justice and the politics of difference. Princeton University Press, 1990.

ZHOU, X.; CHAN, Y.; PENG, Z. Deliberativeness of online political discussion: a content analysis of the Guangzhou Daily website. Journalism Studies, v. 9, n. 5, p. 759, 2008. 